\title{
Perfil de Adolescentes Talentosos e Estratégias para o seu Desenvolvimento ${ }^{1}$
}

\author{
Jane Farias Chagas ${ }^{2}$ \\ Denise de Souza Fleith \\ Universidade de Brasília
}

\begin{abstract}
RESUMO - O objetivo dessa pesquisa foi examinar características cognitivas, acadêmicas, afetivas e sociais de adolescentes talentosos e identificar fatores que favorecem ou dificultam o desenvolvimento de suas habilidades, a partir da percepção dos indivíduos talentosos, de seus familiares e professores. Participaram do estudo quatro adolescentes talentosos, 12 familiares e cinco professoras. A entrevista semiestruturada foi utilizada como instrumento. Os resultados indicaram que as características cognitivas e acadêmicas mais reconhecidas foram: autodidatismo, facilidade para aprender e dedicação aos estudos. Entre as características afetivas e sociais, destacaram-se: determinação, timidez e preferência pelo isolamento social. Os fatores promotores do desenvolvimento do talento mais frequentes foram: suporte familiar e atendimento em sala de recursos. A principal barreira identificada foi o acesso a serviços especializados.
\end{abstract}

Palavras-chave: adolescentes; talento; superdotação, família, estratégias educacionais.

\section{Profile of Talented Adolescents and Strategies for their Development}

\begin{abstract}
The purpose of this study was to examine cognitive, academic, affective and social characteristics of talented adolescents, and to identify factors that promote or inhibit the development of their abilities, based on their perception and of their family and teachers. Four talented students, 12 family members and five teachers participated in the study. A semi-structured interview was used as instrument. The results indicated that the most acknowledged cognitive and academic characteristics were: Autodidactism, easiness to learn, and dedication to studies. Among the affective and social characteristics, the ones highlighted were: determination, shyness, and preference for social isolation. Frequently indicated factors that promote talent development were: Family support and services in the resources room. The main barrier was the access to specialized services.
\end{abstract}

Keywords: adolescents; talented; giftedness, family, educational strategies.

Uma boa parte das pesquisas realizadas com indivíduos talentosos ainda está centralizada no período da infância, em situação escolar ou familiar, por breves períodos de tempo e com pouca consideração das interconexões multidimensionais que envolvem os processos de desenvolvimento ao longo do tempo. O estudo do talento com base nos pressupostos do desenvolvimento humano é recente e se traduz em um dos desafios para a área (Chagas, 2008; Subotnik, 2003).

A partir desta perspectiva, estudos com adolescentes talentosos são relevantes por preencherem lacuna percebida na literatura quanto ao desenvolvimento do talento no curso de vida. A compreensão dos processos que caracterizam essa etapa evolutiva lança luz sobre as mudanças, tendências ou interesses dinâmicos que orientam o desenvolvimento para novas direções, ações e emoções (Oliva, 2004a, 2004b). Isto indica que o desenvolvimento do talento, como ocorre com outras características humanas, é contínuo, dinâmico e multifacetado.

Ademais, o talento envolve a interação de capacidades individuais associadas a componentes multidimensionais do contexto sócio-histórico-cultural. A definição adotada neste estudo é baseada em modelo multifatorial, desenvolvido por Renzulli e Reis (1997), denominado Modelo dos Três Anéis e as expressões talento, superdotação e altas habilidades são

1 Apoio: CAPES.

2 Endereço para correspondência: Quadra 05, Conjunto F, Casa 53 Sobradinho-Brasília - DF. CEP: 73030056.Email: janefcha@gmail. com consideradas como sinônimos. Neste modelo, o talento ou os comportamentos de superdotação são demonstrados na intersecção de três fatores: habilidades gerais ou específicas acima da media, criatividade e envolvimento com as atividades relacionadas a áreas de interesse ou habilidade.

Há algumas características típicas de crianças talentosas que podem ser acentuadas durante a adolescência e impactar de forma importante a interação com os pares (Lee, 2002). Entre os atributos que influenciam a socialização do adolescente talentoso destacamos aqueles assinalados por Winner (1998) e Lee (2002): precocidade no desenvolvimento físico, cognitivo e social, altos níveis de atenção e concentração, memória de reconhecimento exacerbada, preferência por novidades, linguagem oral avançada.

Há autores que sugerem que adolescentes talentosos, especialmente aqueles com habilidades extremas, apresentam maior vulnerabilidade a problemas emocionais e sociais e maiores riscos para a depressão, ansiedade e ideação suicida (Gross, 2002; Jackson \& Peterson, 2003; Neihart, 2006; Peterson, 2001). Os resultados conflitantes com relação ao ajustamento emocional e social de adolescentes talentosos apresentados na literatura podem ser explicados, em parte, pela diversidade metodológica utilizada, pelo foco em fatores endógenos, exógenos e estressores específicos, e pelo estudo de subgrupos de indivíduos talentosos (Osborne \& Kenny, 2005; Richards, Encel \& Shute, 2003).

É importante ressaltar que os adolescentes talentosos não constituem um grupo homogêneo (Alencar \& Fleith, 
2001; Chagas \& Fleith, 2009; Sabatella, 2005). Portanto, o desenvolvimento de suas habilidades, a qualidade de vida e o seu sucesso ou a autorrealização dependem de um conjunto complexo de variáveis individuais e ambientais, especialmente aquelas relacionadas ao contexto familiar e escolar. Esses fatores organizam uma teia específica ou fluxo de influências significativas entre o processo-pessoa-contexto-tempo (Chagas, 2008). Inegavelmente, são muitos os desafios enfrentados pelas famílias de adolescentes talentosos, entre eles o de lidar com as habilidades avançadas, a competitividade entre irmãos, os comportamentos incompatíveis com o que é esperado para a idade cronológica e as demandas por educação e atendimentos especializados (Chagas, 2003). A escola é outro sistema de fundamental importância no desenvolvimento do talento na adolescência, uma vez que é responsável pela estruturação e acesso a oportunidades. O objetivo dessa pesquisa foi, portanto, examinar características cognitivas, acadêmicas, afetivas e sociais de adolescentes talentosos e identificar fatores que favorecem ou dificultam o desenvolvimento de suas habilidades, a partir da percepção do indivíduo talentoso, de seus familiares e professores. Espera-se que este estudo possa fornecer subsídios a gestores que atuam na elaboração de políticas públicas e a educadores que atendem alunos superdotados, bem como orientar pais na implementação de práticas favoráveis ao desenvolvimento do talento de seus filhos.

\section{Método}

\section{Participantes}

Participaram deste estudo quatro adolescentes, seus familiares e professoras. Os adolescentes foram selecionados com base no pareamento de dados demográficos, tipo de talento, posição na família, constelação familiar e renda familiar a partir de uma amostra de 42 adolescentes, investigada em projeto anterior. Foram considerados adolescentes talentosos os alunos que frequentavam um Programa de Atendimento ao Aluno Superdotado e que possuíam idade entre 12 e 18 anos.

Dos quatro adolescentes que participaram da pesquisa, dois tinham 12 anos e os outros dois tinham 16 e 18 anos, sendo dois de cada gênero. Os adolescentes mais velhos ocupavam a posição de segundo filho e os mais novos eram caçulas. Todos os adolescentes eram talentosos na área de artes visuais. Com a finalidade de manter em sigilo a identidade desses adolescentes, ao longo desse trabalho, eles serão chamados pelos codinomes: Jorge (12 anos), Adalberto (16 anos), Naiana (12 anos) e Elisa (18 anos).

Participaram do estudo quatro mães, três pais e cinco irmãos. Três famílias tinham constelação familiar semelhante: pai, mãe e três filhos (sendo um deles gemelar) e uma família era constituída de pai, mãe e duas filhas. Essas famílias possuíam renda mensal que variava entre 10 e 15 salários mínimos. Os pais eram casados pela primeira vez com uma média de tempo civil de 20 anos, que variava entre 19 e 21 anos. Todas as famílias residiam em casa própria no perímetro urbano. Um pai não participou da coleta de dados devido a questões relacionadas à sua jornada de trabalho.
As mães $(n=4)$ tinham idade media de 44,7 anos, que variava entre 44 e 46 anos. O nível de escolaridade materno era: ensino fundamental incompleto, ensino fundamental completo, graduação completa e pós-graduação incompleta. Os pais $(\mathrm{n}=3)$ tinham idade média de 47,5 anos, que variava entre 40 e 52 anos. O nível de escolaridade paterno era ensino fundamental incompleto, ensino fundamental completo e ensino médio completo. Os irmãos dos adolescentes $(\mathrm{n}=5)$ tinham idade media de 18,2 anos que variava entre 14 e 22 anos. Desses, quatro eram do gênero feminino e um do gênero masculino. O nível de escolaridade fraterno era ensino fundamental incompleto $(n=1)$, graduação incompleta nas áreas de informática e educação física $(n=2)$ e pré-vestibular $(n=2)$.

Participaram do estudo cinco professoras, sendo três da sala de recursos ${ }^{3}$ e duas do ensino regular. As professoras das salas de recursos eram formadas na área de artes plásticas e tinham um tempo de atuação no magistério de nove, 13 e 24 anos, respectivamente. Essas professoras tinham idade media de 46,3 anos, variando de 41 a 50 anos. As professoras do ensino regular tinham, respectivamente, 27 e 53 anos de idade. Uma tinha sete anos de atuação no magistério e era formada em pedagogia; a outra tinha 33 anos de atuação no magistério e era formada em Letras-Português. As professoras foram selecionadas entre aqueles professores que atendiam os alunos à época da pesquisa.

\section{Instrumento}

Foram utilizados protocolos de entrevistas semiestruturadas elaborados pela primeira autora. $\mathrm{Na}$ versão dos pais e adolescentes, o roteiro era composto por questões abertas que discorriam sobre as características individuais e familiares, aspectos relacionados ao diagnóstico e às práticas parentais, rede de apoio social, expectativas futuras, dinâmica familiar e conceito de talento e superdotação. Os demais protocolos de entrevistas direcionados aos irmãos e professoras continham perguntas abertas sobre os mesmos aspectos.

\section{Procedimento}

Os quatro adolescentes, seus familiares e professoras preencheram o termo de consentimento livre e informado, autorizando a entrevista e agendando os melhores dias e horários para a realização da coleta de dados. As entrevistas foram realizadas individualmente, com cada membro da família, na casa dos participantes e em local onde a privacidade pudesse ser mantida. Concomitantemente à realização das entrevistas com as famílias, foram agendadas as entrevistas com as professoras. Estas entrevistas foram realizadas individualmente, na escola onde atendiam na sala de recursos ou em sala reservada. Todas as entrevistas foram gravadas em formato MP3 e transcritas posteriormente. Para o exame dos dados obtidos na coleta de dados foi utilizada a técnica de análise de conteúdo (Bardin, 1977).

3 Serviço de apoio pedagógico especializado oferecido, via de regra, no período contrário ao que o aluno está matriculado na escola regular. $\mathrm{O}$ atendimento é realizado por professor especialista em educação especial e possui espaço físico equipado para o desenvolvimento de atividades adequadas às características do aluno (Ministério da Educação, 2006). 


\section{Resultados}

Os resultados são apresentados a partir das características cognitivas, acadêmicas, afetivas e sociais percebidas pelo adolescente talentoso da área de artes visuais, seus familiares e professores. Também nesta seção são descritas as estratégias (individuais, educativas ou pedagógicas, suporte familiar e rede de apoio social) que favorecem o desenvolvimento do talento e as barreiras identificadas para a sua promoção.

\section{Características Cognitivas}

Os resultados demonstraram que a característica cognitiva percebida de forma mais evidente nos adolescentes de nossa pesquisa foi a capacidade de aprender coisas com rapidez, facilidade, autonomia e autodidatismo $(\mathrm{f}=11)$. Essa categoria aparece na fala dos adolescentes ( $f=4)$, mães $(f=1)$ irmãos $(f=3)$ e professoras da sala de recursos $(f=3)$. As professoras do ensino regular não se manifestaram a respeito dessa característica. A capacidade de aprender foi relacionada a qualquer tema ou disciplina acadêmica e não estava reduzida à área de talento. Nesse sentido, a mãe do Adalberto declarou acerca do filho: "Aprendeu ali sozinho, praticando, percebia que ele tinha um avanço cognitivo, quando ele criticava (...). A professora também enxergou isso nele".

Os adolescentes revelaram com relação às características cognitivas como era o processo mental em que se envolviam durante a elaboração de desenhos. Eles descreveram processos semelhantes. A partir de estímulos internos ou externos, elaborava-se uma imagem mental que era repassada para o papel, sendo explorada até que houvesse uma correspondência entre o que foi pensado e o que estava sendo executado. Para Naiana, esse processo era iniciado a partir de uma motivação intrínseca que a impulsionava na elaboração ou detalhamento de seus desenhos. Jorge descreveu um processo inverso, quando a partir de um estímulo visual, ele criava algo original. Além dos processos mentais, Adalberto acrescentou que alguns fatores externos, como a presença de outras pessoas, que interferiam de forma negativa no processo de desenhar. Daí sua preferência por desenhar à noite, quando não seria interrompido.

\section{Características Acadêmicas}

Entre as características acadêmicas foram evidenciadas dedicação aos estudos e às tarefas escolares $(f=12)$ e desempenho escolar acima da média $(\mathrm{f}=10)$, em contraponto com a dificuldade em algumas disciplinas $(f=4)$. A dedicação aos estudos e tarefas escolares foi frequente na fala dos familiares (mães, $\mathrm{f}=3$; pais, $\mathrm{f}=5$; irmãos, $\mathrm{f}=1$ ) e das professoras (sala de recursos, $f=1$; ensino regular, $f=2$ ). Essa categoria foi definida como uma iniciativa própria do adolescente em ser assíduo na escola e optar por fazer as tarefas escolares com esmero e capricho.

O desempenho escolar acima da média foi uma categoria presente na fala de adolescentes ( $f=2)$, mães ( $f=6$ ), pais ( $f$ $=1)$ e professoras da sala de recursos $(\mathrm{f}=1)$ sendo definida como tirar notas acima da média, estar adiantado na escola, não ter sido reprovado em nenhuma série ou ocupar posição de destaque na escola. A dificuldade em algumas disciplinas foi contrastada com o desempenho escolar acima da media, principalmente pelas mães $(\mathrm{f}=3)$ dos adolescentes do gênero masculino e uma professora do ensino regular $(f=1)$. As dificuldades mencionadas estavam vinculadas a disciplinas e conteúdos específicos e não a área de talento ou habilidade do aluno.

\section{Características Afetivas}

Quando perguntados sobre as características afetivas de adolescentes talentosos, vários traços motivacionais, de personalidade e afetivos foram mencionados, entre eles: determinação ( $f=12)$, timidez $(f=9)$, responsabilidade, maturidade e seriedade, ( $f=8$ ), o envolvimento com sua área de interesse e habilidade $(\mathrm{f}=8)$, perfeccionismo $(\mathrm{f}=6)$, tranquilidade $(\mathrm{f}=5)$, criatividade $(\mathrm{f}=4)$ e bom humor $(\mathrm{f}=4)$.

A determinação foi uma característica mais frequente na fala dos irmãos e apontada como um diferencial entre ambos (irmãos, $\mathrm{f}=7$; mães, $\mathrm{f}=2$; pais, $\mathrm{f}=2$; professoras da sala de recursos, $f=1)$. Essa categoria foi definida como o desejo deliberado em fazer algo, ausência de dúvidas sobre projetos futuros e atividades a serem executados. A timidez foi um traço percebido em três adolescentes talentosos - Elisa, Adalberto e Naiana - e relacionada à introspecção, reserva e ao fato de serem sistemáticos (mães, $\mathrm{f}=3$; pais $\mathrm{f}=1$; irmãos $\mathrm{f}=2$; professoras da sala de recursos, $\mathrm{f}=3$ ).

A responsabilidade, maturidade e seriedade foram características atribuídas aos quatro adolescentes por mães ( $\mathrm{f}$ $=5)$, pais $(f=2)$ e professoras da sala de recursos $(f=1)$. Essas características foram delineadas como uma atitude positiva e proativa frente à vida e aos objetivos traçados pelos próprios adolescentes. $\mathrm{O}$ envolvimento com a área de interesse e habilidade foi um aspecto reconhecido como foco permanente entre os adolescentes (mães, $f=4$; irmãos, $f=2$, professoras do ensino regular, $\mathrm{f}=2$ ). $\mathrm{O}$ perfeccionismo foi descrito em relação aos quatro adolescentes como o desejo e a intenção de fazer as coisas da forma mais perfeita possível (mães, $\mathrm{f}=2$; pais, $\mathrm{f}=1$; irmãos, $\mathrm{f}=2$; professora da sala de recurso, $f=1)$. A tranquilidade foi associada pelas professoras $(f=4)$ e um pai $(f=1)$ ao fato de o aluno ser atendido em suas necessidades especiais. A criatividade também foi uma característica percebida nos quatro adolescentes e vinculada à área de interesse, maneira de lidar com o tempo livre e de manipular objetos (irmãos, $\mathrm{f}=3$; professoras da sala de recursos, $f=2$ ). $\mathrm{O}$ bom humor foi apontado pelos irmãos como uma característica exclusiva dos adolescentes do gênero masculino $(f=4)$. Esse atributo foi descrito como a habilidade de fazer rir, gostar de brincar e ser engraçado. Os adolescentes, exceto o Adalberto, não discorreram sobre suas características afetivas.

\section{Características Sociais}

Com relação às características sociais sobressaíram a preferência pelo isolamento social $(\mathrm{f}=16)$, a tendência a negar o talento $(f=10)$ e a relação interpessoal harmoniosa $(f=12)$ em termos gerais, porém parcialmente conflituosa 
com os irmãos $(f=5)$. A preferência pelo isolamento social foi descrita como preferência por realizar atividades de forma solitária, possuir poucos amigos e manter diálogo restrito com seus pares (adolescentes, $\mathrm{f}=3$; mães, $\mathrm{f}=6$; pais, $\mathrm{f}=2$; irmãos, $\mathrm{f}=4$, professoras da sala de recursos, $\mathrm{f}=1$ ). Essa característica parecia ser cultivada pelos adolescentes desde a infância, sendo valorizada e favorecida pelas práticas e estilos parentais. Os pais viam no isolamento um fator protetor com relação a vários riscos como: drogas, gravidez precoce e marginalidade; ao passo em que monitoravam os relacionamentos dos filhos na escola e em outros ambientes sociais, definindo o nível de proximidade e intimidade com pares da mesma idade.

O isolamento social era percebido pelos adolescentes como uma estratégia que contribua para o aperfeiçoamento das habilidades de desenho e para torná-los mais fortes diante das adversidades. Esse entendimento pode ser exemplificado pela fala do Adalberto: "Esse isolamento me ajudou muito, muito, muito. Por exemplo, se acontecer alguma coisa muito ruim comigo, o que eu vou falar: de novo! Isso não é nada pra mim, não me influencia em nada". Essa preferência também aparece associada ao local de residência das famílias que não propiciava o brincar coletivo. Esse fato motivou o brincar solitário ou com parentes próximos.

A tendência a negar o talento foi uma categoria exclusiva da fala dos quatro adolescentes $(f=6)$, sendo expressa como uma tentativa de demonstrar desempenho médio nas disciplinas escolares e área de talento com a finalidade de manter relações interpessoais mais harmoniosas e receber menor cobrança do pares. Com relação às relações interpessoais, os genitores (mães, $\mathrm{f}=4$; pais, $\mathrm{f}=3$ ) e professoras da sala de recursos $(\mathrm{f}=3)$, descreveram que eram harmoniosas, cooperativas e amistosas com pais e pares. No entanto, três dos quatro adolescentes revelaram possuir relacionamento competitivo com seus amigos mais próximos. Não se tratava de uma competição acirrada ou negativa, mas orientada no sentido ou desejo de superar o outro. Geralmente, esses amigos tinham habilidades e interesses semelhantes, fato que nutria a amizade e os interesses comuns e gerava o aperfeiçoamento da habilidade de desenhar.

Entre os irmãos, as relações foram consideradas parcialmente conflituosas, na percepção de três irmãos $(f=3)$, um pai ( $f=1)$ e uma mãe $(f=1)$. Durante a infância esses episódios foram associados à disputa por brinquedos e atenção parental. Na adolescência, entre as queixas ressaltadas pelos irmãos foram destacadas: a busca por individualidade, a resistência à autoridade fraterna dos irmãos mais velhos, a mudança de postura do adolescente talentoso após seu diagnóstico e o fato de se tornarem alvos de comparações entre parentes e pares. Apesar disso, relataram que tiravam proveito das habilidades daqueles pedindo-lhes para que ilustrassem trabalhos escolares $(\mathrm{f}=3)$ e aprendendo com as experiências e interesses que tão vividamente compartilhavam em casa $(f=3)$. Os irmãos $(f=3)$ e pais $(f=4)$ também relataram que nutriam profunda admiração pela competência técnica e a produção do adolescente, motivo de satisfação e orgulho para eles e para a família como um todo.

Além das características afetivas e sociais, emergiu da fala dos participantes alguns aspectos relacionados ao desenvolvimento infantil e adolescente que têm impacto sobre o desen- volvimento e reconhecimento do talento, principalmente, no ambiente escolar. A precocidade foi a principal característica do desenvolvimento infantil apontada pelos participantes (mães, $\mathrm{f}=4$; pais, $\mathrm{f}=4$; irmãos, $\mathrm{f}=3$; professoras da sala de recursos, $\mathrm{f}=1$ ), sendo relacionada à área de interesse do adolescente e aos aspectos ligados à aquisição das habilidades de leitura e escrita. Ao compararem crianças e adolescentes talentosos, foram salientadas diferenças na riqueza de detalhes da produção artística precoce e maior facilidade dos professores em reconhecerem o talento da criança (adolescentes, $\mathrm{f}=2$; mães, $\mathrm{f}=3$; professoras, $\mathrm{f}=3$ ). Essa diferença no reconhecimento do talento na escola durante a infância e adolescência pode ser exemplificada a partir do depoimento do Adalberto: "Na escola, de apoio sobre o meu talento, pelo menos agora no ensino médio, eu não tenho nenhum! Agora, antigamente, no ensino fundamental, os professores já buscavam o aluno que tinha talento, já achavam ótimo".

Na mesma direção, três adolescentes e duas professoras da sala de recursos relataram um nível de cobrança mais acerbado sobre os adolescentes quando comparados com as crianças. Na opinião desses participantes, a criança talentosa desperta admiração e sua condição é vista como uma vantagem. No entanto, o talento do adolescente implica uma demonstração cada vez mais excepcional de suas competências e habilidades. Essa cobrança foi apontada como um fator tanto endógeno como exógeno associado ao talento. Essa percepção pode ser resumida pela declaração do Adalberto, ao ser questionado se é mais fácil ser uma criança ou um adolescente talentoso: "Bem é mais fácil ser criança... $\mathrm{O}$ que as pessoas vão dizer? "Ah, esse menino tem talento, sabe desenhar, que bonitinho! Que fofo, que bom!". Agora, o adolescente, não, já que ele sabe desenhar, não vão aceitar pouca coisa dele".

\section{Estratégias para o Desenvolvimento do Talento}

Entre as estratégias implementadas no sentido de favorecer o desenvolvimento do talento foram identificados quatro fatores relevantes: estratégias individuais, estratégias educativas ou pedagógicas, suporte familiar e rede de apoio social.

Com relação às estratégias individuais foram apontados a atitude positiva frente a adversidades $(f=6)$ e o gerenciamento de tempo e das oportunidades para o aperfeiçoamento do talento em artes visuais $(\mathrm{f}=4)$. Estas duas categorias são exemplificadas pelo que relatou Naiana acerca do seu acesso ao atendimento em sala de recursos: "demorou esse tempão pra me chamarem, mas eu nunca desisti. Eu sempre procurava alguma coisa para fazer, assim, cursos, algumas coisas assim, para nunca parar". O mesmo pode foi relatado por Elisa: "Em qualquer hora vaga, quando eu podia ter um papel, eu estava desenhando. Quanto mais você desenha, você aperfeiçoa o traço". Na mesma direção, discorreu Adalberto: "Eu não faço dever de escola em casa. Mas, geralmente, eu tento fazer tudo de uma vez e num tempo só (...) Agora, sobre os desenhos: eu gosto de fazer meus desenhos à noite".

Entre as estratégias educativas ou pedagógicas ( $\mathrm{f}=55$ ) foram destacados o atendimento em sala de recursos ( $\mathrm{f}=$ 43) e a participação em eventos como exposições, concursos, visitas a museus e apresentação de trabalhos $(f=12)$. 
$\mathrm{O}$ atendimento em sala de recursos foi apresentado como um dos aspectos mais favoráveis para o desenvolvimento do talento sendo entendido pelos participantes como um "divisor de águas". As principais mudanças relatadas a partir do atendimento na sala de recursos, na percepção dos adolescentes, seus familiares e professoras, estavam associadas ao reconhecimento e valorização do talento ( $\mathrm{f}$ $=16)$, aperfeiçoamento das habilidades superiores $(f=8)$, mudança na rotina individual e familiar $(\mathrm{f}=6)$ e acesso a oportunidades $(f=6)$. Outras mudanças mencionadas com menor frequência foram o maior nível de cobrança $(\mathrm{f}=3)$, mais habilidade para lidar com os sentimentos $(f=2)$, maior produtividade e melhora nos relacionamentos $(\mathrm{f}=2)$. Essas atividades também modificaram a rotina individual e familiar, uma vez que requeriam um maior envolvimento familiar com as atividades e eventos promovidos pela sala de recursos e a reformulação na distribuição das atividades domésticas (adolescentes, $\mathrm{f}=3$; mães, $\mathrm{f}=1$; irmãos, $\mathrm{f}=2$ ).

A participação em eventos, exposições e concursos foi outro fator considerado preponderante no desenvolvimento do talento (adolescentes, $\mathrm{f}=6$; mães, $\mathrm{f}=2$; pais, $\mathrm{f}=2$; professoras da sala de recursos, $f=2$ ). Todos os alunos informaram a participação em exposições e três já haviam sido premiados em concursos de poesias ou desenho. Nesse sentido, a mãe do Jorge relatou: "Fiquei apaixonada pelo desenho, pra mim aquilo é um sonho muito grande. Às vezes tem coisas que a gente nem acredita. Eu vi o Jorge desenhar, mas eu não sabia que ele poderia chegar onde ele está chegando".

O suporte familiar foi percebido pelos adolescentes, seus familiares e professoras como o fator de maior impacto no desenvolvimento do talento. Esse suporte foi definido em termos do estilo parental $(\mathrm{f}=37)$ e práticas parentais $(\mathrm{f}=$ 16). O estilo parental mais propício para o desenvolvimento do talento envolvia um conjunto de atitudes como o reconhecimento, elogio, valorização, monitoramento e incentivo parental ao desenvolvimento do talento, associados a aspectos disciplinares baseados no diálogo, altas expectativas e responsividade, classificados como essenciais por adolescentes $(f=8)$, mães $(f=11)$, pais $(f=6)$, irmãos $(f=5)$, professoras da sala de recursos $(f=5)$ e professoras do ensino regular $(\mathrm{f}=2)$.

Na mesma direção, as práticas parentais foram relacionadas à priorização da educação pela família (mães, $\mathrm{f}=3$; pais, $\mathrm{f}=4$; irmãos, $\mathrm{f}=1$ ) e à intervenção materna nos processos de encaminhamento e identificação (adolescentes, $\mathrm{f}=3$; mães, $\mathrm{f}=3$; pais, $\mathrm{f}=2$ ). As práticas parentais de priorização da educação eram bastante coerentes com os estilos parentais. Além do investimento parental no atendimento das demandas por recursos materiais específicos e de transporte dos adolescentes, os pais não mediam esforços para manterem seus filhos na escola. Eles também estabeleciam parcerias com os professores a fim de que seus filhos tivessem condições de produzirem seus trabalhos artísticos.

A intervenção materna foi um fator apontado como marcante no desenvolvimento do talento, na opinião dos adolescentes ( $f=3)$, mães $(f=3)$, pais ( $f=4)$ e irmão ( $f=$ 1). Três mães foram diretamente responsáveis pelo processo de encaminhamento dos adolescentes para o atendimento em sala de recursos. Essas mães eram vistas por seus filhos como as maiores incentivadoras e divulgadoras do talento.
Essa influência fica bastante evidente no relato do Adalberto: "uma coisa que influenciou e marcou foi o incentivo da minha mãe em falar que eu sou melhor do que os outros em alguma coisa, que eu tenho um dom". E, ainda "minha mãe me ajudou muito. Quando eu estou fazendo um desenho, eu termino o desenho. Aí, chega a minha mãe e fala: tem que desenhar direito, tem que entregar no prazo, tem que mostrar serviço. Quer que eu melhore sempre".

Na percepção das duas adolescentes, o desenvolvimento do talento feminino pode ser negligenciado se não houver a intervenção materna favorável. Nesta direção, argumenta Naiana: "Tem muitas mães que falam assim: a minha filha desenha, mas ela precisa ficar em casa, para ajudar a mãe, cuidar dos irmãos".

Com relação à rede de apoio social, representada pelos vizinhos, amigos e comunidade religiosa, esses atores sociais funcionam como divulgadores e consumidores primários da produção de indivíduos talentosos. São agentes que os reconhecem como talentosos, que fortalecem sua autoestima e autoconceito e que, portanto, devem receber mais informações por meio de disseminação de conhecimentos específicos sobre a área (adolescentes, $\mathrm{f}=2$; mães, $\mathrm{f}=4$ e pais, $\mathrm{f}=3$ ).

Os resultados demonstraram ainda que entre as expectativas relacionadas ao futuro dos adolescentes talentosos sobressaíram aquelas associadas à carreira e profissão (adolescentes, $\mathrm{f}=5$; mães, $\mathrm{f}=3$; pais, $\mathrm{f}=4$; professoras da sala de recursos, $f=3$ ), ao reconhecimento e valorização do talento (adolescentes, $\mathrm{f}=2$; mães, $\mathrm{f}=2$; pais, $\mathrm{f}=1$; professoras da sala de recursos, $f=4$; professora do ensino regular, $f=1$ ) e ao aperfeiçoamento do talento (adolescentes, $f=2$; mães, $\mathrm{f}=1$; professoras da sala de recursos; $\mathrm{f}=1$; irmãos, $\mathrm{f}=4$ ). É importante ressaltar, que aspectos relacionados à carreira e à profissão estavam presentes no ideário de todos os adolescentes da nossa pesquisa.

\section{Barreiras Encontradas com Relação ao Desenvolvimento do Talento}

Os adolescentes, seus familiares e professoras apresentaram algumas barreiras ao desenvolvimento do talento que precisavam ser superados. Três macrocategorias de barreiras emergiram dos relatos: educacionais $(f=44)$, institucionais ou políticas $(f=29)$ e de difusão ou disseminação do conhecimento sobre o talento $(\mathrm{f}=12)$. As principais barreiras educacionais identificadas foram: a dificuldade de acesso ao programa (adolescentes, $\mathrm{f}=4$; mães, $\mathrm{f}=10$; pai, $\mathrm{f}=1$; irmãos, $\mathrm{f}=2$; professoras da sala de recursos, $\mathrm{f}=2$; professoras do ensino regular, $\mathrm{f}=5$ ); a formação ineficiente dos professores do ensino regular (adolescentes, $\mathrm{f}=4$; mães, $\mathrm{f}=4$; irmãos, $\mathrm{f}$ $=1$; professoras: sala de recursos, $\mathrm{f}=2$; ensino regular, $\mathrm{f}=$ 4), a descontinuidade do atendimento após o encerramento da educação básica (professoras da sala de recursos, $\mathrm{f}=4$ ). Outras categorias exclusivas da fala das professoras com frequência igual ou menor a 2 foram: a rotatividade de professores no ensino regular, quantidade de alunos em sala de aula, o excesso de atividades administrativas que atrapalha as atividades pedagógicas e práticas pedagógicas tradicionais.

As barreiras institucionais ou políticas foram associadas às dificuldades de acesso a programas voltados para 0 
desenvolvimento do talento e descritas como: escassez de políticas públicas (adolescentes, $\mathrm{f}=2$; mães, $\mathrm{f}=3$; pais, $\mathrm{f}=$ 1 ; professora do ensino regular, $\mathrm{f}=1$ ); falta de apoio institucional (mães, $\mathrm{f}=4$; pai, $\mathrm{f}=1$; irmão, $\mathrm{f}=1$; professoras da sala de recursos, $\mathrm{f}=4)$, falta de acesso ao mercado de trabalho (adolescente, $\mathrm{f}=1$; mães, $\mathrm{f}=2$; pai, $\mathrm{f}=1$; professoras da sala de recursos, $\mathrm{f}=4$ ) e a falta de oportunidade ou de espaço adequado para mostrar o talento (adolescente, $\mathrm{f}=1$; mãe, $\mathrm{f}$ $=1$; pai, $\mathrm{f}=1$; irmão, $\mathrm{f}=1$ ).

As barreiras pertinentes à difusão ou disseminação do conhecimento na área do talento emergiram como desconhecimento do tema pelos professores e autoridades (mãe, $\mathrm{f}$ $=1$; pai, $\mathrm{f}=1$; irmão, $\mathrm{f}=1$; professoras da sala de recursos, $\mathrm{f}=2$; professoras do ensino regular $(\mathrm{f}=2)$ e a pouca valorização ou reconhecimento do talento pela sociedade em geral (adolescentes, $\mathrm{f}=2$; mães, $\mathrm{f}=1$; irmãos, $\mathrm{f}=2$ ).

\section{Discussão}

As principais características cognitivas e acadêmicas percebidas nos adolescentes talentosos desta pesquisa foram dedicação aos estudos e facilidade para aprender. Esses atributos favorecem o desempenho escolar acima da média, especialmente nas áreas de talento do adolescente ou em áreas correlatas. Winner (1998) e Csikszentmihalyi, Rathunde e Walen (1993) ressaltam a necessidade que os indivíduos talentosos têm para dominar assuntos de seu interesse e o fato de aprenderem com instrução mínima. Esse fascínio pelo domínio de conhecimentos gerais ou específicos de um campo do conhecimento, em certa medida, retroalimenta o autodidatismo, a rapidez na aquisição de informações, a apreensão correta de conceitos e a capacidade de absorção acima da média. A intensidade com que esses adolescentes se dedicam a aprender pode levá-los também ao estado de fluxo que é caracterizado por altos níveis de satisfação, alta concentração e perda da noção de tempo. Esse estado, segundo Csikszentmihalyi (1996), é decisivo para o desenvolvimento do talento, uma vez que leva a pessoa a se comprometer durante bastante tempo com o domínio de habilidades.

A participação na sala de recursos foi indicada como uma das experiências mais marcantes na promoção do desenvolvimento do talento. Esse resultado ressalta a importância de atendimento adequado e especializado ao adolescente talentoso e o seu envolvimento em eventos socioculturais. Nesse sentido, vários pesquisadores (Alencar, 2007; Fleith, 2007a) têm alertado sobre o mito de que o indivíduo talentoso possui recursos suficientes para desenvolver sozinho o seu potencial. É de extrema importância a ampliação da oferta de oportunidades que visem o desenvolvimento e o reconhecimento do talento (Chagas, 2008; Magalhães, 2006).

As características intelectuais, afetivas e motivacionais dos adolescentes talentosos, reveladas nesse estudo são corroboradas pela literatura (Chagas, 2007, 2008; Csikszentmihalyi, 1996; Fleith, 2007b; Winner, 1998). Esse conjunto de características individuais também parece em consonância com a literatura sobre indivíduos resilientes. Entre os traços convergentes realçamos aqueles apontados por Wolin e Wolin (citados em Kotliarenco, Cáceres \& Fontecilla, 1997) e Molina-Loza (2003): (a) introspecção, associada à meta- cognição, (b) independência, (c) habilidade para relacionar-se, (d) iniciativa no sentido de exercer controle sobre os problemas, (e) humor, e (f) criatividade.

A resiliência é um fator intimamente associado à capacidade de enfrentamento e adaptação frente às situações adversas. É multideterminada e um produto da interação de forças que atuam em um contexto ecossistêmico de desenvolvimento (Kotliarenco et al., 1997). Essa relação pode ser inferida, a partir do depoimento dos adolescentes e seus familiares, especialmente, com relação ao enfrentamento das dificuldades de acesso a oportunidades de atendimento, na maneira como lidavam com as situações adversas e com as barreiras ao desenvolvimento do talento. É importante ressaltar que as características individuais não concorrem isoladamente para os comportamentos ou traços resilientes. Esses atributos estão associados a variáveis sócio-histórico-culturais (Kotliarenco et al., 1997; Waller, 2001).

Em relação às características sociais, cabe destacar certa dicotomia associada às relações interpessoais dos adolescentes talentosos, principalmente com os irmãos, pares e amigos mais íntimos. Apesar de essas relações serem percebidas como "normais", a adesão ao grupo de pares parece ser obtida em detrimento do desenvolvimento das habilidades superiores dos adolescentes, uma vez que os adolescentes talentosos descreveram a tendência a negar o talento como uma estratégia adaptativa. Como explica Winner (1998), com base nos estudos de Csikszentmihalyi et al. (1993), os adolescentes talentosos "parecem ter problemas, não devido a alguma dificuldade social ou emocional inerente, mas antes porque são tão diferentes dos outros, eles parecem 'dessincronizados'. Se pudessem encontrar outros como eles, é bem possível que seus problemas sociais desaparecessem" (p. 179).

Os resultados também evidenciaram que as famílias com adolescentes talentosos têm a sua dinâmica modificada em função das características do adolescente e do seu atendimento em sala de recursos, o que encontra respaldo em estudo realizado por Zajonc (2001). A precocidade desses indivíduos impingiu à família expectativas sobre o desempenho, ao mesmo tempo em que o atendimento em sala de recursos reconfigurou, em alguns casos, a divisão das tarefas domésticas, a utilização do tempo livre e aumentou a demanda por acompanhamento parental. Nesse sentido, o monitoramento e engajamento parental tiveram um impacto positivo no aperfeiçoamento das habilidades dos adolescentes talentosos. A intervenção materna, em especial, foi um fator imprescindível no encaminhamento desses jovens ao Programa de Atendimento ao Aluno Superdotado. As mães foram consideradas as principais incentivadoras e divulgadoras da produção do adolescente. Resultados semelhantes sobre a intervenção materna foram encontrados por Shumow (1997).

Os resultados que demonstraram que os genitores conjugavam altas expectativas com relação ao desempenho do adolescente talentoso com diálogo, disciplina e monitoramento estão em consonância com a literatura. Esses pais possuíam um estilo parental que mesclava exigência e autoridade (Aspesi, 2007; Winner, 1998), encorajavam e incentivavam os filhos a vencerem desafios e a se manterem engajados naquilo que gostavam de fazer (Bloom, 1985; Csikszentmihalyi et al., 1993). Eles também investiam tempo e recursos, em parceria 
com os professores da sala de recursos, para uma produção de qualidade e o acesso a oportunidades. Eles reconheciam e valorizavam o talento dos filhos e eram consumidores e divulgadores da produção do adolescente. Essas atitudes e práticas são de forma análoga descritas por outros autores (Aspesi, 2007; Chagas, 2003, 2007; Winner, 1998).

A preferência pelo isolamento social parece ser fomentada pelos estilos e práticas parentais, pelo tipo de talento e pelas características afetivas e intelectuais dos adolescentes talentosos. A associação desses fatores deve ser objeto de estudos futuros para o estabelecimento dessas relações. Essa preferência é relatada por vários indivíduos criativos e talentosos como condição inerente ao processo criativo (Root-Bernstein \& Root-Bernstein, 2001) e parece corroborar resultados encontrados por Csikszentmihalyi (1996) e Csikszentmihalyi et al. (1993).

As peculiaridades da relação fraternal dos adolescentes de nossa pesquisa e as suas demandas por individualidade, autonomia e novas oportunidades vinculadas ao atendimento na sala de recursos, sugere a importância dos ambientes compartilhados e não-compartilhados no desenvolvimento do talento. De acordo com Simonton (2002), o ambiente compartilhado é aquele que todos os irmãos partilham e vivenciam juntos, no mesmo lar e com os mesmos pais. $\mathrm{O}$ ambiente não-compartilhado é exclusivo de cada irmão e é responsável por tudo aquilo que não pode ser atribuído à hereditariedade. Essa constatação parece corroborar os resultados encontrados por Csikszentmihalyi et al. (1993) que verificaram que os adolescentes talentosos se envolviam com atividades relacionadas ao seu domínio de talento por uma quantidade de tempo superior quando comparados a outros adolescentes.

A escola regular, representada pela sala de aula regular, práticas pedagógicas e sistema de gestão, foi percebida como despreparada e negligente no atendimento das necessidades especiais do aluno talentoso, principalmente durante a adolescência. Os adolescentes, suas famílias e suas professoras reconheceram a formação inadequada dos professores como uma barreira para a identificação de adolescentes talentosos e sua efetiva inclusão educacional.

A comunidade, constituída dos vizinhos, parentes e participantes dos mesmos grupos religiosos, foi mencionada como rede de apoio social importante na divulgação, consumo e disseminação da produção dos adolescentes talentosos. Os adolescentes relataram a importância de serem reconhecidos por esses agentes, uma vez que o prestígio entre esses atores fortalecia a percepção do próprio adolescente sobre si mesmo e confirmava o reconhecimento da família.

Entre as principais barreiras ao desenvolvimento do talento foram citadas o acesso ao Programa de Atendimento ao Aluno Superdotado, a formação insuficiente de professores do ensino regular, a escassez de políticas públicas e apoio institucional. Corroborando Ambrose (2006), chamamos a atenção para aspectos macrossistêmicos que influenciam na criação e manutenção de oportunidades socioculturais que promovem o desenvolvimento do talento e das aspirações de jovens talentosos. O contexto econômico, sociopolítico e as ideologias das classes dominantes exercem controle na mídia, na dimensão ética e nos sistemas interpretativos e de valores de uma sociedade. Esses são fatores que provêem uma enorme vantagem para o desenvolvimento do talento de alguns indivíduos, mas que do mesmo modo podem se transformar em uma barreira opressiva para outros. Com isso, os indivíduos talentosos oriundos de ambientes com privação socioeconômica ou que nasceram em comunidades segregadas ou estigmatizadas têm menor acesso a oportunidades socioculturais. Esses aspectos vêm à tona, especialmente, no relato sobre os esforços empreendidos pela família concentrados em aspectos básicos como aquisição de recursos materiais específicos adequados e transporte, necessários para uma produção de qualidade e sua posterior disseminação.

A importância da relação mesossistêmica entre família e escola, para os processos de desenvolvimento do talento, torna imprescindível a formação continuada das pessoas envolvidas nesses microssistemas. Pais e professores são os primeiros agentes mobilizadores para o provimento das necessidades especiais de indivíduos talentosos durante a infância e a adolescência. $\mathrm{O}$ investimento em ações educativas e a disseminação do conhecimento científico produzido na área constituem uma grande demanda para atenção e atendimento de indivíduos talentosos de forma adequada e especializada.

Finalmente, é preciso considerar toda a complexidade de ser adolescente talentoso nesse início do século XXI. Há riscos e situações, sem contraponto na história, que precisam ser solucionados e superados (Giddens, 2000). Por isso, é cada vez mais urgente que jovens e adolescentes respondam a esses desafios e encontrem seu lugar nessa teia sócio-histórico-cultural. Isso torna ainda mais relevante o papel da família e da escola nos processos de desenvolvimento do potencial dos adolescentes, e, em particular, daqueles que são talentosos, pois "nenhuma pessoa isolada, por maior que seja a sua estatura, poderosa sua vontade, penetrante sua inteligência, consegue transgredir as leis autônomas da rede humana da qual provêm seus atos e para a qual eles são dirigidos" (Elias, 1994, p. 48).

\section{Referências}

Alencar, E. M. L. S. (2007). Indivíduos com altas habilidades/ superdotação: clarificando conceitos, desfazendo idéias errôneas. In D. S. Fleith (Ed.), A construção de práticas educacionais para alunos com altas habilidades/superdotação (Vol.1, pp. 16-23). Brasília: MEC/SEESP.

Alencar, E. M. L. S., \& Fleith, D. S. (2001). Superdotados: determinantes educação e ajustamento (2a. ed.). São Paulo: EPU.

Ambrose, D. (2006). Aspiration growth, talent development, and self-fulfillment in a context of democratic erosion. Roeper Review, 28, 11-19.

Aspesi, C. C. (2007). A família do aluno com altas habilidades/ superdotação. In D. S. Fleith (Ed.), A construção de práticas educacionais para alunos com altas habilidades/superdotação (Vol. 3, pp. 29-47). Brasília: MEC/ SEESP.

Bardin, L. (1977). Análise de conteúdo. Lisboa: Edições 70.

Bloom, B. S. (1985). Developing talent in young people. New York: Ballantine. 
Chagas, J. F. (2003). Características familiares relacionadas ao desenvolvimento de comportamentos de superdotação em alunos de nível sócio-econômico desfavorecido. Dissertação de Mestrado, Universidade de Brasília, Brasília.

Chagas, J. F. (2007). Conceituação e fatores individuais, familiares e culturais relacionados às altas habilidades. In D. S. Fleith \& E. M. L. S. Alencar (Eds.), Desenvolvimento de talentos e altas habilidades (pp. 15-24). Porto Alegre: Artmed.

Chagas, J. F. (2008). Adolescentes talentosos: Características individuais e familiares. Tese de Doutorado, Universidade de Brasília, Brasília.

Chagas, J. F., \& Fleith, D. S. (2009). Estudo comparativo sobre superdotação com famílias em situação sócio-econômica desfavorecida. Revista Brasileira de Educação Especial, 15, 155-170.

Csikszentmihalyi, M. (1996). Creativity: flow and the psychology of discovery and invention. New York: Harper Collins.

Csikszentmihalyi, M., Rathunde, K., \& Whalen, S. (1993). Talented teenagers: The roots of success \& failure. New York: Cambridge University Press.

Elias, N. (1994). A sociedade dos indivíduos. Rio de Janeiro: Zahar.

Fleith, D. S. (Org.). (2007a). A construção de práticas educacionais para alunos com altas habilidades/superdotação (Vol. 2- 4). Brasília: MEC/SEESP.

Fleith, D. S. (2007b). Altas habilidades e desenvolvimento sócioemocional. In D. S. Fleith \& E. M. L. S. Alencar (Eds.), Desenvolvimento de talentos e altas habilidades (pp. 41-50). Porto Alegre: Artmed.

Giddens, A. (2000). Mundo em descontrole. Rio de Janeiro: Record.

Gross, M. U. M. (2002). Social and emocional issues for exceptionally intellectually gifted students. In M. Neihart, S. M. Reis, N. M. Robinson \& S. M. Moon (Eds.), The social and emotional development of gifted children: What do we know? (pp. 19-32). Washington, DC: Prufock Press.

Jackson, P. S., \& Peterson, J. S. (2003). Depressive disorder in highly gifted students. Journal of Secondary Gifted Education, 14, 175-186.

Kotliarenco, M. A., Cáceres, I., \& Fontecilla, M. (1997). Estado de arte en resiliencia. Washington, DC: Organización Panamericana de la Salud. Organización Mundial de la Salud.

Lee, S. Y. (2002). The effects of peers on the academic and creative talent development of a gifted adolescent male. The Journal of Secondary Gifted Education, 15, 19-29.

Magalhães, M. G. M. S. (2006). Programa de atendimento ao superdotado da Secretaria de Estado de Educação do Distrito Federal (1991-2002): inclusão social ou tergiversação burocrática? Tese de Doutorado, Universidade de Brasília, Brasília.

Ministério da Educação. (2006). Sala de recursos multifuncionais: espaço para atendimento educacional especializado. Brasília: MEC/SEESP.
Molina-Loza, C. A. (2003). Resiliência: um olhar diferente sobre a tragédia humana. Trabalho apresentado na VI Conferência Internacional de Filosofia, Psiquiatria e Psicologia, Brasília, DF.

Neihart, M. (2006). Achievement/affiliation conflicts in gifted adolescents. Roeper Review, 28, 196-202.

Oliva, A. (2004a). Desenvolvimento da personalidade na adolescência. In C. Coll, A. Marchesi \& J. Palacios (Eds.), Desenvolvimento psicológico e educação (Vol. 1, pp. 335-349). Porto Alegre: Artes Médicas.

Oliva, A. (2004b). Desenvolvimento social durante a adolescência. In C. Coll, A. Marchesi \& J. Palacios (Eds.), Desenvolvimento psicológico e educação (Vol. 1, pp. 350-367). Porto Alegre: Artes Médicas.

Osborne, M. S., \& Kenny, D. T. (2005). Development and validation of a music performance anxiety inventory for gifted adolescent musicians. Journal of Anxiety Disorders, 19, 725-751.

Peterson, J. S. (2001). Gifted and at risk: Four longitudinal case studies of pos-high-school development. Roeper Review, 24, 31-39.

Renzulli, J. S., \& Reis, S. M. (1997). The Schoolwide Enrichment Model: A how-to guide for educational excellence (2a ed.). Mansfield Center, CT: Creative Learning Press.

Richards, J., Encel, J., \& Shute, R. (2003). The emotional and behavioural adjustment of intellectually gifted adolescents: a multi-dimensional, multi-informant approach. High Ability Studies, 14, 153-164.

Root-Bernstein, R., \& Root-Bernstein, M. (2001). Centelhas de gênios: como pensam as pessoas mais criativas do mundo. São Paulo: Nobel.

Sabatella, M. L. P. (2005). Talento e superdotação: problema ou solução? Curitiba: Editora IBPEX.

Shumow, L. (1997). Daily experiences and adjustment of gifted low-income urban children at home and school. Roeper Review 20, 35-38.

Simonton, D. K. (2002). A origem do gênio. Rio de Janeiro: Record.

Subotnik, R. F. (2003). A developmental view of giftedness: From being to doing. Roeper Review, 26, 14-15.

Waller, M. A. (2001). Resilience in ecosystemic context: Evolution of the concept. American Journal of Orthopsychiatry, 7, 1-8.

Winner, E. (1998). Crianças superdotadas: mitos e realidades. Porto Alegre: Artes Médicas.

Zajonc, R. B. (2001). The family dynamics of intellectual development. American Psychologist, 56, 490-496.

Recebido em 23.09.2009

Primeira decisão editorial em 07.02.2011

Versão final em 14.02.2011

Aceito em 06.06.2011 